\title{
O ensino da literatura e a interpretação textual: uma abordagem histórico-cultural
}

\author{
The teaching of literature and textual \\ interpretation: a historic-cultural \\ approach
}

\author{
Sônia M.Machado MIRANDOLA* \\ Maria de Lourdes SPAZZIANI**
}

\begin{abstract}
Resumo: Por meio do estudo aqui enfocado pretende-se investigar a influência da leitura de obras literárias no ensino e aprendizado da Literatura numa escola da rede pública estadual da cidade de Ituverava, interior de São Paulo. A pesquisa desenvolvese com os 34 alunos de uma das segundas séries do Ensino Médio e com a professora de Língua Portuguesa e Literatura da respectiva classe, a partir de uma revisão bibliográfica embasada na perspectiva histórico-cultural, bem como de uma pesquisa empírica do tipo etnográfico, priorizando-se o caráter qualitativo. Realiza-se no contexto escolar, no dia-a-dia das aulas. Os dados são coletados por meio da observação das atividades do grupo analisado, pela aplicação de questionários para detectar a vivência literária dos alunos, por algumas conversas com finalidade feitas com alunos e professora, entrevista com a bibliotecária e análise documental do planejamento anual da professora e das produções dos alunos. As análises revelam que, no grupo estudado, há correlação positiva e mediada entre o hábito da leitura e a produção textual dos jovens, apesar de apresentarem dificuldades na interpretação. Por meio da leitura de obras literárias, o ensino da Literatura incentiva a leitura e a escrita, além de desenvolver o espírito crítico dos alunos. Uma obra literária pode gerar vários caminhos, desde que tenha havido a autopercepção do texto, a apreensão das idéias depreendidas pelo pensamento do narrador.
\end{abstract}

Palavras-chave: literatura. leitura. Língua Portuguesa. Psicologia Histórico-Cultural. Ensino Médio.

\footnotetext{
* Mestre em Educação. Professora da Faculdade de Filosofia, Ciências e Letras de Ituverava, Fundação Educacional de Ituverava. Depto. de Letras. romirandola@netsite.com.br

** Doutora em Educação. Professora do Centro Universitário Moura Lacerda. Ribeirão Preto.spazzian@ig.com.br
}

$$
\text { Olhar de professor, Ponta Grossa, 9(1): 183-199, } 2006 .
$$


ABSTRACT: The aim of the study presented in this article is to investigate the influence of the reading of literary works in the teaching and learning of Literature in a state public school in Ituverava, interior of São Paulo. The research is carried out with thirty-four students of the second year of high school and with a teacher of Portuguese Language and Portuguese Literature. The research starts with a bibliographical review from a historical-cultural perspective as well as with a qualitative ethnographical empirical research. The research is carried out in the school context during the group's daily activities. The data is collected from the observation of the group's activities, from questionnaires aimed at discovering students' experience with literature, from conversations with students and teachers, from an interview with the librarian and also from the analysis of the teacher's annual teaching programme and the students' production. The analysis indicates that in the group studied there is a positive and mediated correlation between the habit of reading and the production of texts by the students despite students' difficulties to interpret texts. By means of literary works, the teaching of literature motivates reading and writing in addition to developing students' critical skills. A literary work may lead to various paths if students' have perceived the text by themselves and grasped the narrator's ideas.

Keywords: literature. reading, Portuguese, Historical-cultural Psychology. High School.

\section{INTRODUÇÃO}

Este artigo, síntese de uma dissertação em âmbito de Mestrado, propõe-se a investigar a influência da leitura de obras literárias no ensino e aprendizado da Literatura. Desenvolve-se a partir de uma revisão bibliográfica embasada na perspectiva histórico-cultural, assim como de uma pesquisa empírica do tipo etnográfico, priorizando o caráter qualitativo. Realiza-se no contexto escolar, no dia-adia das aulas com os alunos e a professora de Língua Portuguesa e Literatura da respectiva classe.

Os instrumentos utilizados para construir os dados da pesquisa constam de um questionário aplicado aos alunos envolvidos para detectar a vivência literária de cada um; observação participante da atuação do professor durante as aulas de literatura, como também do envolvimento dos educandos; análise documental do planejamento anual da professora e das produções dos alunos como interpretações de textos, redações, avaliações; fichamentos de obras literárias e seminários; entrevista com a bibliotecária, e algumas conversas com finalidade ${ }^{1}$ realizadas com alunos, professores e bibliotecária, em recreios e intervalos entre uma aula e outra.

\footnotetext{
${ }^{1}$ Segundo Minayo (1998) conversas com finalidade é a coleta de dados obtida sem um instrumento formal (questionário ou roteiro de entrevista), mas que visa à obtenção de determinadas informações específicas para a análise da pesquisa.
} 
ALITERATURANO ENSINO MÉDIO

Em nenhum instante da história houve tantas inovações como as que estão ocorrendo no momento. O mundo socioeconômico vem sofrendo fortes influências de uma cultura globalizada e exigente. Uma cultura que requer indivíduos cultos e críticos, capazes de enfrentar os problemas de sua época.

Nessa esteira, novos desafios configuram-se à educação e, em especial, à do Ensino Médio, a etapa final do Ensino Básico, considerado o primordial para a formação do educando em relação à aquisição de conhecimentos necessários a uma atuação participante e produtiva. A complexidade das mudanças exige diferentes modalidades de ensino. Todos esperam muito mais da escola como formadora do cidadão. Novas alternativas curriculares são propostas ao Ensino Médio, compromissado com a formação do aluno como pessoa humana que, munido desses conhecimentos, poderá ter condições de se adaptar com flexibilidade às exigências mundiais.

Em relação ao ensino da Literatura, integrada à área de Linguagens, Códigos e suas Tecnologias, após a nova Lei de Diretrizes e Bases da Educação Nacional, Lei 9.394/96, os horizontes estão sendo ampliados ao enfatizar a leitura de obras literárias como fonte do aprendizado. Uma leitura reconhecida como instrumento de comunicação, de interação social e como objeto de reflexão e de análise. A LDB sugere uma inter-relação da Literatura com as Ciências Humanas, Ciências da Natureza e Matemática. Ao invés de hiatos entre as disciplinas, conforme vigorava no passado, sugere-se hoje a criação de elos entre elas (BRASIL, 1999).

As histórias da literatura são transpostas para um outro plano: priorizase, agora, a área da leitura e da análise de textos. Uma leitura vista como atividade humana (SMOLKA, 1995, p. 26). Não se trata simplesmente de despertar a habilidade de ler, mas de a leitura ser vista como forma de linguagem, oriunda das inter-relações humanas, capaz de transformar o indivíduo. Uma leitura como mediação, como prática social, ou seja, uma leitura que capacite o indivíduo a participar ativamente do meio em que vive.

A televisão, o computador e até mesmo o rádio chamaram para si muitas das funções outrora desempenhadas pela leitura, consideradas por alguns menos necessários do que em outros tempos. A transmissão de informações por tais instrumentos de comunicação gera grande economia de tempo, mas será que esses meios estão colaborando para uma melhor compreensão do mundo? Será que estão conduzindo à reflexão, ao questionamento, a uma viagem ao desconhecido, a uma aventura do espírito, tal qual a leitura proporciona? Ler pode ser uma grande viagem, algo que nos faça ir além dos horizontes

Olhar de professor, Ponta Grossa, 9(1): 183-199, $2006 . \overline{185}$ 
imaginados pelo autor. E o importante é que o indivíduo não é passivo, ele não está "vendo" televisão e, sim, está pensando, imaginando, opinando. A literatura de cordel, por exemplo, oriunda das feiras nordestinas, facilita a memorização com o auxílio das rimas e proporciona, muitas vezes, a alfabetização, tanto de seus produtores como dos leitores, ambos com pouca ou nenhuma instrução formal. Ouvindo as histórias contadas por outras pessoas, repetindo-as, memorizando-as, terminam aprendendo a ler e a escrever (ABREU, 1994). Por outro lado, almanaques ou revistas distribuídas geralmente por farmácias, que apresentam um misto de linguagem verbal e não-verbal, cativam a atenção do leitor jovem ou adulto, culto ou inculto, transmitindo-lhe diversificados e interessantes conhecimentos por meio de calendários relacionados aos ciclos vitais, curiosos provérbios, poemas, contos, acontecimentos históricos, conselhos úteis à saúde, fases da lua $\mathrm{e}$ suas influências, anedotas, horóscopos, efemérides. Instruem e, concomitantemente, distraem (PARK, 1999). Já os jornais, com sua coletânea de textos enfocando fatos sóciopolítico-econômicos, proporcionam uma leitura crítica sobre a sociedade local, nacional e internacional. A imprensa, como atesta Canclini (apud PAULINO et al, 2001), vem desempenhando importante papel político-social ao denunciar as mazelas de grupos sociais, fazendo com que se desperte o leitor-cidadão, consciente da necessidade de exercer os seus direitos. Por conseguinte, a leitura, seja a de obras literárias ou não, pode induzir a diferentes aprendizados.

Quanto ao que concerne aos estudos literários, estes podem também proporcionar, no Ensino Médio, através da leitura, a recuperação do patrimônio cultural, o interesse por novas possibilidades de aprendizado, com o fito de atingir uma educação transformadora e responsável, imbuída com a formação e identidade do educando. A leitura, por outro lado, pode, também, ser vista como símbolo de liberdade, alcançada por conquistas culturais, uma forma democrática de adquirir conhecimentos, desde que tenha sido trabalhada, manejada pelo professor de forma incitadora, conduzindo o aluno ao raciocínio, à comunicação e à formação de novos conceitos.

Segundo Vigotsky (1988), o indivíduo não nasce pronto, nem é cópia do ambiente externo. Em seu desenvolvimento há uma interação constante e ininterrupta entre processos internos e influências do mundo social. Em parte, esse desenvolvimento é conseqüência da maturação do organismo e, em parte, do contato com um determinado ambiente cultural. A trajetória do desenvolvimento humano é realizada de fora para dentro. Dessa forma, o indivíduo não se faz sozinho, há toda uma gama de influências que lhe proporcionará o desenvolvimento de todas suas potencialidades. Como assevera Vigotsky (1998), o 
desenvolvimento humano realiza-se através de um processo dialético entre as condições biológicas e as condições sociais. Se não houver o contato, a participação do indivíduo com um determinado ambiente cultural, não haverá o desenvolvimento dos processos internos superiores. É o aprendizado que o conduz a novos tipos de comportamentos, que o impulsiona ao desenvolvimento.

A aprendizagem e o desenvolvimento estão concatenados desde a infância, através da integração ao meio social, o qual age sobre o indivíduo e, ao mesmo tempo, é por ele influenciado. Observando, perguntando e recebendo respostas, a criança desenvolve-se mental e intelectualmente. Entretanto, se o ambiente não for desafiador, se não estimular a inteligência do educando, ele não desenvolverá totalmente sua capacidade de raciocínio. Uma coisa é transmitir conhecimentos abstratos; outra é levar o educando a vivenciar uma dada realidade, a participar de algo e a resolver problemas. Um ambiente rico, diversificado, instigador de práticas educativas, provavelmente proporcionará um crescimento maior e, em conseqüência disso, desenvolvimento e aprendizagem ocorrerão simultaneamente.

A LDB, como já se disse, configura uma nova abordagem ao Ensino Médio - os conteúdos tradicionais de ensino de regras, conceitos, nomenclaturas gramaticais e histórias da literatura são deslocados para um segundo plano. $\mathrm{O}$ estudo da gramática pas- sa a ser um meio para a compreensão, interpretação e produção de textos e a Literatura coaduna-se ao mundo da leitura. Assim, através da leitura de obras literárias, ocorre um lento processo de formação do leitor de Literatura e do competente produtor de texto.

O papel do educador, nesse caso, não é apenas o de transmitir informações, mas o de convidar seus alunos à reflexão, à participação e à ação. São trabalhadas estruturas flexíveis com diversas possibilidades de construção e de reconstrução a fim de chegar a novos conhecimentos. Finalidade essa que se encaixa também aos propósitos do ensino da Literatura no Ensino Médio. Um ensino pautado em realizações humanas, por ser a literatura uma atividade humana, uma expressão de pensamentos e idéias socialmente valorizadas sobre o mundo, sujeita a variações e a contradições.

Diante dessas expectativas, novas competências e habilidades são esperadas em decorrência da educação e, em particular, do aprendizado da Literatura. Vista como documento de uma época, a literatura reflete o contexto social no qual está inserida e, como tal, será analisada por meio da transmissão sóciocultural. . Aquele ensino teórico, somente da história dos movimentos literários, sem relação com as obras dos autores, sem a análise dessa obras, é relegado a um outro plano. Hoje, a Literatura passa a ser compreendida e interpretada por meio da leitura. Uma leitura dialógica, 
contextualizada e, sobretudo, interdisciplinar.

Dialógica, já que implica comunicação, interação. Ao ler, o indivíduo não está passivo, não está simplesmente vendo televisão, mas sim refletindo, concordando, contestando, criticando, esclarecendo dúvidas, interpretando e até tentando alçar novos horizontes para os quais o autor nem tenha, talvez, imaginado.

Contextualizada, pois como afirmam Vigotsky (1988) e Wallon(1975), uma leitura somente será agradável para o aluno se estiver relacionada aos seus interesses, às suas necessidades.

Interdisciplinar, conforme constata Fazenda (2001),porque é preciso que ocorra um diálogo entre uma disciplina e outra, que se construam pontes entre elas, a fim de facilitar o aprendizado e promover uma interação de conhecimentos.

Para compreender um texto não basta simplesmente lê-lo. É preciso que se dê novos significados a ele. Um texto pode gerar várias janelas, pode sugerir diversos caminhos, desde que tenha sido compreendido. "Compreensão refere-se à potencialidade de Ser e de conhecer aquilo de que se é capaz", segundo Martins (in SILVA, 2000, p. 26). Esse conhecimento não é proveniente apenas de uma autopercepção do texto, mas resultante de um estado de consciência, de uma consciência presente. Da compreensão chega-se à interpretação, ou seja, à possibilidade de apropriação e de apreensão do que foi compreendido. Na compreensão não ocorre apenas o que os fatos representam, mas também a intenção, as idéias que se depreendem do pensamento do narrador. Quando a compreensão torna-se conceitual, ou possível de ser conceituada, ocorre a interpretação.

\section{A PESQUISA}

Logo no início do contato com os alunos da classe, através de conversas com finalidade e observação do cotidiano da turma, identificamos obras literárias que circulam de forma livre ou planejada. Notamos que a maioria possui, entre seus materiais escolares, romances dos mais variados gêneros. Ao serem inquiridos sobre esses livros, respondem que os retiram da biblioteca da escola. Consistem em leituras agradáveis escolhidas por eles, como: "Natureza selvagem," de Jon krakawer; "O vampiro de Susse,", de Sherlock Holmes; "O senhor dos anéis", de J. R.R. Tolkien; "Através do espelho", de Jostein Gaarder; "Harry Potter e o prisioneiro de Ackaban", de J.K.Rouhig.; "Romeu e Julieta", "Otelo", "O rei Lear" de Sheakespeare e outros.

Declaram os alunos que lêem por gosto, que são leituras interessantes, diferentes das exigidas pelos professores. De certa forma, suas leituras influenciam em suas maneiras de pensar, de agir e, inclusive, facilitam no desempenho escolar, principalmente, na elaboração de redações.

Além dessas leituras livres, os alu- 
nos lêem os livros estipulados pela professora para serem apresentados à sala por meio de seminários. Ao todo são vinte livros. Cada um dos grupos apresenta cinco livros em cada bimestre. A escolha é realizada por sorteio; logo, algumas obras ao serem expostas à classe, não corresponderão ao conteúdo estudado. No entanto, nota-se no momento da explanação dos seminários que nem todos os alunos dos grupos leram os livros. Apenas os que apresentam, os que explicam o conteúdo das obras lidas, um ou dois alunos, de cada um dos grupos, demonstram conhecer bem o assunto. Os que não leram alegam ser leituras cansativas, desinteressantes, além de impostas.

Em relação às leituras livres, selecionadas diretamente com a bibliotecária, não há interferência da professora; portanto, nenhuma relação se estabelece entre educadora e educandos sobre elas. Não há aproveitamento dessas prazerosas leituras, como os próprios alunos dizem. Para Geraldi (1984,p. 96), o aluno-leitor não é passivo, mas o agente que busca significações. Nesta procura de diferentes respostas para compreender o mundo que o cerca, tais leituras, se discutidas, comentadas poderiam cumprir tal objetivo, como também, se relacionadas a outras obras e a diferentes estéticas literárias, poderiam elucidar o aprendizado literário. Dessas leituras chegar-se-ia às mais complexas, às solicitadas pela professora e exigidas nos vestibulares. A profes- sora, por sua vez, seria o que realmente deve ser, a interlocutora de seus alunos - aquela que questiona, pergunta e auxilia na resolução de problemas (GERALDI, 1984,p. 96).

A seguir destacamos, a fim de elucidar o presente artigo, um episódio realizado por docente e alunos sobre os períodos literários, salientando elementos da dinâmica inter-subjetiva em aulas expositivas e em seminários.

O Episódio: O Romantismo

No dia 24 de abril, de 2002, em uma quarta -feira, a professora inicia os estudos sobre o Romantismo, o primeiro movimento literário atinente ao conteúdo programático da segunda série do Ensino Médio.

A professora pede a um aluno que leia o poema "Como eu te amo", de Gonçalves Dias.

Prof $^{\mathrm{a}}$ : Fernando, leia o poema para nós. Silêncio, prestem atenção!

(O aluno inicia a leitura, lendo pausadamente)

Como eu te amo

Como se ama o silêncio, a luz, o aroma,

O orvalho numa flor, nos céus a estrela, No largo mar a sombra de uma vela, Que lá na extrema do horizonte assoma;

Como se ama o clarão da branca lua, Da noite, na mudez os sons da flauta, As canções saudosíssimas do nauta, Quando em mole vaivém a nau flutua;

(O aluno faz uma pausa mais longa, recupera o fôlego e recomeça a 
leitura, entrecortada pelos comentários dos colegas, dizendo estar cansado).

\footnotetext{
Como se ama das aves o gemido, Da noite as sombras e do dia as cores Um céu com luzes, um jardim com flores, Um canto quase em lágrimas sumido;
}

Como se ama o crepúsculo da aurora , A mansa viração que o bosque ondeia, $\mathrm{O}$ sussurro da fonte que serpeia

Uma imagem risonha e sedutora;

Como se ama o calor e a luz querida, A harmonia, o frescor, os sons, o céus, Silêncio, e cores, e perfume e vida Os pais e a pátria e as virtudes e a Deus:

Assim eu te amo, assim; mais do que podem Dizer-to os lábios meus, mais do que vale Cantar a voz do trovador cansada: $\mathrm{O}$ que é belo, o que é justo, santo e grande Amo em ti. _. Por tudo quanto sofro, Por quanto já sofri, por quanto ainda Me resta sofrer, por tudo eu te amo

(Dias, in Maia, 2000, p. 192)

Ao terminar, um aluno pergunta: O que é assoma e nauta?

Antes que a professora responda, um colega lhe diz:

Você não está vendo o vocabulário aí ao lado? Tem essas palavras e mais algumas.

O aluno lê em voz alta: nauta navegador, marinheiro; assomar aparecer, surgir.

Não sei por que eles usavam palavra tão difícil, naquela época! (replica uma aluna )

Prof: : Todas estas palavras se encontram no vocabulário. Leiam , vocês podem até substituir com as palavras sinônimas para entender melhor. Hoje vamos falar sobre a vida de Gonçalves Dias. Ele é o principal representante da primeira geração romântica, também chamada Indianismo... Vocês já sabem por que é assim chamada, não é?

Sim, nós já estudamos essa parte. (responde um aluno)

O índio é visto como o herói nacional nessa época, não é? (pergunta uma aluna)

Muito bem, é isso mesmo. E quem melhor retratou isso no Romantismo foi Gonçalves Dias. Além de exaltar o índio, canta a pátria, a natureza, o retorno ao passado histórico, o amor e a religião. Pelo texto lido vocês podem observar que em sua obra há um exagerado sentimentalismo, próprio dos românticos. (relata a professora)

Agora, vamos observar quais as características românticas que aparecem no texto.

Lúcia : Amor à pátria.. (responde a aluna)

Eri : Presença de rimas.

Fernanda : Idealização da mulher.

Prof : Será que no Romantismo há necessidade de rimas?

Eri: Ah! Não sei...mas esta é uma característica desse movimento, então deve ter.

Prof : Não há necessidade de rimas neste movimento. Rimas não são características do Romantismo.

Vocês já observaram se ocorre o saudosismo? Onde será que está?

Cris: Será que é na segunda estro- 
fe, aí fala em canções saudosistas do nauta?

Profa: Isso mesmo. Está correto.

Infelizmente, a professora prendese às características do movimento literário; sempre que está se soltando, explorando o significado do texto, termina referindo-se às características e quase não há referências ao contexto da época.

Segundo Geraldi (1985, p. 95), “a linguagem compreende um lugar de interação, onde sujeitos se formam pelo processo dialógico". Assim, professor e aluno, nas aulas de Língua Portuguesa e Literatura devem ler, falar, discutir, analisar fatos e escrever.

Em seguida, os alunos, sentados à vontade, em grupos, devido à irrisória quantidade de livros existentes na sala, lêem o texto, discutem sobre as dúvidas que surgem e vão respondendo às questões propostas pelo livro didático que, por sinal, exploram também as características do Romantismo: 1- O eu-lírico utiliza comparações para expressar o seu sentimento amoroso. Que elementos, bem ao gosto do estilo romântico, predominam nessas comparações? 2- A religiosidade - outra característica da primeira fase - está presente no poema. Destaque o verso que exemplifica essa afirmação. 3- Em que verso o nacionalismo romântico está presente através de uma comparação?

Por conseguinte, trata-se de propostas insignificantes: não conduzem à interpretação das mensagens emitidas pelo poeta; à percepção dos as- pectos semânticos; à compreensão dos motivos que o levaram a se expressar daquele modo.

Simultaneamente, alguns alunos conversam baixinho, enquanto outros lêem as obras literárias escolhidas por eles mesmos na biblioteca da escola. Surpreendemo-nos com a rapidez e entusiasmo com que lêem esses livros.

Para se ensinar Literatura não basta simplesmente ler textos e relacionálos às características dos respectivos movimentos literários, é preciso que se vá além, ou seja, que se explore o sentido do texto, o sentido das palavras. Para Bakhtin (1986), a palavra desprovida de seu significado, de seu conteúdo, restringe-se ao significante, ao processo fisiológico de sua formação.

Um ensino pautado numa mera descrição, tal qual o ensino tradicional voltado somente para o conhecimento teórico e abstrato, em que se priorizam somente as características básicas do texto, não conduz à atividade mental dos sujeitos. Infelizmente, esse ensino tem resistido ao tempo, deixando marcas indeléveis. Formada no final da década de 1980, a professora de Língua Portuguesa e Literatura da classe pesquisada fez todos os seus estudos, o Fundamental, o Magistério e o Universitário, em uma época em que o ensinar enfocava a transmissão de conhecimentos. As matérias eram vistas como um fim em si mesmas, com uma programação a ser cumprida pelo aluno, o qual era considerado um receptor passivo, que nada sabia. 
O professor, cuja palavra era a mesma do livro, era considerado o doador do saber. Diante disso, a professora não consegue, em alguns momentos, desligar-se dessa prática pedagógica anacrônica de cunho tecnicista e instrumental, cuja meta é a racionalização do ensino a fim de atingir determinados objetivos. Supõe-se que o educando, ao ouvir e fazer exercícios repetitivos, memoriza os conteúdos e os aplica em diferentes situações (Libâneo, 1992).

Segundo Salgado (2000), até poucas décadas não se concedia a devida importância aos cursos de formação de professores, não se salientavam os aspectos teóricos da educação nem a formação geral: tais cursos estribavamse, quase sempre, apenas na metodologia. Com o advento da Lei $\mathrm{n}^{\circ}$ $5.692 / 71$ proliferaram-se as escolas, tanto as denominadas Habilitação para o Magistério, como as de nível superior. Em virtude disso, ocorreram transformações significativas na educação, muitas das quais acarretam decadência do ensino, já que "os currículos caíram no esquema do imediatismo, com a inevitável carga de superficialidade e compartimentalização do saber" (SALGADO, op. cit, p. 16).

Se antes da referida Lei já ocorria a hipertrofia dos aspectos instrumentais em detrimento do conteúdo básico, geral e específico, após a mesma todos esses dados não foram enfocados convenientemente, como atesta Salgado (op. cit.). O Magisté- rio deixou a desejar em relação ao conteúdo científico e aos enfoques metodológicos, defasagem essa que perdurou por toda década de 1980 .

Formada nesses idos, a professora traz consigo seqüelas dessa formação tradicional, o que faz com que, em alguns momentos, principalmente nos estudos literários, apegue-se à transmissão dos conhecimentos, de informações, esquecendo-se de explorar o sentido, o significado do texto e de relacioná-lo ao contexto histórico-social em que foi produzido.

Conforme Gomes (1994), para que haja aproveitamento de uma leitura, é preciso trabalhá-la, questioná-la, levar o aluno a levantar hipóteses e a refletir sobre elas. A autora relata uma pesquisa feita com alunos do Ensino Médio sobre o conto de Guimarães Rosa, "A Hora e Vez de Augusto Matraga". Segundo ela, os alunos prendem-se apenas às ações das personagens, confundindo-as, muitas vezes, com pessoas da vida real. Os alunos deixam de observar os aspectos relativos à pergunta "como": Como é a linguagem? Como está organizado o texto? Como se relacionam as várias perspectivas? (Gomes, 1994, p. 34). Tais inobservâncias acarretam o não entendimento da linguagem poética. É por isso que, às vezes, o aluno diz não ter entendido nada do que leu; ou seja, não conseguiu fazer os relacionamentos intratextuais nem extratextuais. A leitura foi realizada da mesma forma como se assiste a algum fato, ou a um programa da TV, sem 
busca do significado, sem raciocínio.

Pelas respostas colhidas no questionário aplicado à classe, constatase que os educandos gostam de ler revistas, jornais, livros dos mais variados gêneros, como também reconhecem a leitura como uma ferramenta valiosa para desvendar os mistérios da vida com maior encantamento, senão também como construtora do conhecimento. Apesar de estarem sempre lendo um desses livros, escolhidos por eles ou indicados pelos colegas ou mesmo pela bibliotecária da escola, demonstram, às vezes, desinteresse nos estudos literários. Não compreendem o que lêem, não conseguem, muitas vezes, penetrar no âmago de um texto lido durante a aula. Os próprios alunos dizem: "Nunca pensamos igual a esses poetas, a gente acha que é uma coisa, vai ver é outra completamente diferente".

Por outro lado, presa ao livro didático, a professora restringe-se, por meio de pequenos diálogos, a uma ínfima exploração dos sentidos que emergem do texto. Concentra-se nas informações transmitidas, nos conteúdos e não no literário, na recriação da realidade. Esse poema - Como eu te amo - por exemplo, pode estar se referindo à própria vida do autor, ou melhor, ao amor frustrado de Gonçalves Dias pela dama Ana Amélia, jovem a quem amou por toda sua vida. Impedido de concretizar seus sonhos amorosos por ser mestiço, o poeta extrapola sua dor em belos poemas em que une a temática amorosa à na- tureza: "Como se ama o calor e a luz querida / como se ama o crepúsculo da aurora / como se ama das aves o gemido" (MOISÉS, 2000, p.168).

Se ao invés de falar sobre a vida e a obra do poeta, a professora solicitasse aos alunos uma pesquisa sobre os dados teóricos da literatura, os quais, após apresentados, poderiam gerar um debate,certamente o tema seria mais interessante e motivador. Os próprios alunos descobririam os problemas vivenciados pelo poeta, compreenderiam melhor sua obra e estariam também desenvolvendo a capacidade intelectual e discursiva.

Segundo Kanitz (2003, p. 20), as escolas brasileiras excedem em teorias e informações, porém pouco ensinam como usar essas informações aprendidas: "O ideal seria produzir livros didáticos menos didáticos e mais motivadores, que estimulassem a curiosidade e fossem mais relacionados com a vida futura dos educandos".

Inclusive na entrevista feitas com a bibliotecária, observamos ser a leitura livre apreciada pelos educandos, os quais visitam freqüentemente a biblioteca, trocam idéias tanto com a bibliotecária como com os colegas a respeito dos livros, discutem e estão sempre lendo algo de que gostam, que lhes agradam, sem interferência dos professores. Muitas vezes, a bibliotecária organiza listas de espera para a leitura de certos livros mais cobiçados pelos alunos.

Essas leituras descompromissadas, sem imposições, podem contri- 
buir de forma significativa para o hábito de ler, além de proporcionar ao aluno uma maior compreensão da vida. Segundo pesquisas recentes, realizadas pelo Instituto Paulo Montenegro (2002), entidade criada pelo Ibope em parceria com a Organização Não-governamental Ação Educativa, o jovem brasileiro possui competências de leitura num nível bem rudimentar no tocante à compreensão das idéias gerais. Correspondem aos analfabetos funcionais, pessoas teoricamente alfabetizadas, mas que não sabem o que lêem nem o que escrevem. Segundo Daniel Moreira (2002, p. 11), “essa expressão - analfabeto funcional - é a que melhor caracteriza o indivíduo despreparado para a vida na sociedade da palavra escrita". Hoje o indivíduo precisa mais do que simplesmente ler ou escrever um bilhete para conviver em um grupo social. Dessa forma, leituras escolhidas pelos próprios alunos devem ser estimuladas nas escolas, pois podem constituir um dos caminhos para minimizar o grande número de iletrados existentes no Brasil.

Em conversas com finalidade com os alunos responsáveis pelo seminário, constatamos que nem todos os participantes leram a obra estipulada: "Esse livro não atende o nosso gosto", disseram. Por outro lado, alegaram não ter havido uma orientação prévia da professora quanto à maneira de se processar a leitura, como organizar o seminário. Ela apenas determinoulhes o roteiro para a elaboração do fichamento das obras, quando pode- ria ter indicado a cada um dos integrantes um determinado aspecto para ser analisado. Assim agindo, envolveria todo o grupo, motivando-os a ler.

Dialogando, como diz Vidal (2001, p. 96), numa explosão de falas, professora e alunos descobririam uma nova sensibilidade - o prazer de a leitura proporcionar uma aventura intelectual pelo mundo da Literatura. Seria uma forma de até banir o livro didático, que tanto escraviza o aluno e mecaniza o ensino.

Assim enfocada, a literatura assim enfocada não é vista como atividade discursiva, como diz Smolka (1995). A palavra oral e escrita, da forma como está sendo explorada, não constitui um instrumento de desenvolvimento cultural nem do pensamento. Não conduz a outros caminhos, a novos significados.

Como atesta Azevedo (apud Vidal, 2001, p. 90),

o livro de texto, na escola tradicional, é o centro, em torno do qual gravitam todas as atividades escolares que se sucedem, na ordem de distribuição da matéria segundo suas sugestões metodológicas [...] o livro-padrão, o instrumento a que o aluno se escraviza.

Os alunos lêem, porém, quase não ocorrem diálogos com a palavra escrita, a fim de conduzir à reflexão. Como diz Dewey (apud VIDAL, p. 91):

o livro também pode produzir saber desde que a matéria apresentada suscite a pesquisa e a reflexão e não seja como um alimento intelectual inteira- 
mente preparado para ser absorvido e assimilado como se fosse uma conserva comprada num armazém.

As chaves para a interpretação envolvem participação, apropriação e transformação de significados possíveis. Juntos, professora e alunos, em uma leitura literária, querem seja esta solicitada ou escolhida por eles mesmos, podem refletir, questionar, estudar das prováveis conotações, para se chegar a um consenso.

"As obras literárias apresentadas à classe, em forma de seminários, constituem ricas fontes para se trabalhar a literatura como prática discursiva," afirma Smolka (apud Braga, 2000, p. 92). Ao investigar os aspectos gramaticais, semânticos, os tipos de textos, os gêneros literários, o estilo individual e o de época, a linguagem literária, a intertextualidade com outras obras, os diferentes temas abordados, estar-se-á justamente trabalhando essa prática.

A primeira obra apresentada foi um conto realista; a segunda, um romance e a terceira, um poema, ambas do romantismo; entretanto, nada foi dito, nada foi comentado.

O seminário - palavra de origem latina proveniente de seminal, sêmen, ou seja, o que produz, o que cria, expressa; por conseguinte, centro de criação ou de produção, grupo de estudos em que em todos os participantes debatem uma matéria, produzem algo - constitui um procedimento metodológico que permite uma constante troca de experiências sobre di- ferentes leituras efetuadas, como também, avaliar se houve a compreensão e a transformação de significados. Após este, são recomendáveis debates e dramatizações, tendo o professor a função de animador e de estimulador da manifestação oral de diferentes interpretações das obras lidas (RÖSING, 1988, p. 118).

\section{CONSIDERAÇÕES FINAIS}

Tendo-se em vista o objetivo proposto na pesquisa enfocada, qual seja, o de investigar o ensino e a aprendizagem da Literatura no Ensino Médio por meio dos pressupostos da psicologia histórico-cultural, os resultados pautados, provenientes das formas de trabalho desenvolvidas durante as aulas de Língua Portuguesa e Literatura, como também as mudanças comportamentais do grupo de alunos em observação, possibilitam indicar alguns rumos freqüentes nesse tipo de aprendizado.

Foram comprovados, por meio do questionário aplicado à sala, pelas conversas com finalidade feitas com a professora e os educandos, pela entrevista com a bibliotecária pela análise documental, que a maioria dos alunos apreciam a leitura, que lêem constantemente livros, revistas, jornais, gibis e atribuem importância ao ato de ler. Conseqüentemente, adquirem imaginação criadora, vocabulário rico, diversificado que impelem a se saírem bem nas produções textuais.

Por se tratar de aulas de produ- 
ção, a professora explora mais os significados, as mensagens oriundas do texto, comparando-as com a época atual. Todos opinam, discutem sobre o assunto e, logo após, produzem criativos textos.

Já, a apresentação dos seminários por grupos de alunos, não impele à descoberta, ao questionamento, ao diálogo. Um ou dois alunos do grupo, os que leram a obra, explicam para a classe o fichamento feito. Falam da forma como entenderam e a professora não os contradiz; limita-se a inquiri-los sobre meros fatos. Dos grupos constituídos por nove a dez alunos, apenas um ou dois alunos lêem os livros estipulados, ou restringem-se à leitura dos resumos encontrados nos livros didáticos.

Pelas observações realizadas, podemos inferir que a leitura é uma atividade constante entre eles, pois visitam freqüentemente a biblioteca da escola, optando pelas mais variadas leituras. Todavia, essas leituras - principalmente as paradidáticas, conforme as citadas na página nove deste artigo - realizadas sem interferência da professora, como também as solicitadas por ela para serem apresentadas à sala, por meio de seminários, embora lhes proporcionem enriquecimento da criatividade, como os próprios alunos dizem, quase não os auxilia na compreensão e interpretação dos próprios textos literários analisados durante as aulas.

Os alunos lêem, mas continuam as dificuldades para a compreensão os códigos da língua, os quais constituem um empecilho para perceber o que está implícito nas entrelinhas. Não conseguem perscrutar além do que está à sua frente.

Durante as aulas de Literatura, após as explanações, a professora, na análise textual, restringe-se à identificação das características literárias do respectivo movimento estudado e, a seguir, solicita que os alunos resolvam as atividades propostas pelo livro didático.

Ora, a nova Lei de Diretrizes e Bases da Educação Nacional amplia os estudos literários ao enfatizar a leitura como fonte do aprendizado, ao reconhecê-la como mediadora, como propulsora do conhecimento. Porém, para tal intento, urge que essa leitura seja estimuladora, interessante para o aluno e provocadora do raciocínio.

Os alunos reconhecem o valor da leitura, sua importância, porém não conseguem penetrar no âmago de um texto literário, não o decodificam, não o vêem com um mundo de possibilidades, capaz de múltiplos significados. Cabe, pois, à escola modificarse. É preciso que ela se conscientize de sua missão social, compromissada com o ato de educar, de orientar os alunos, ensinando-os a desvendar barreiras, a cruzar mares desconhecidos. E um dos prováveis caminhos pode ser o resgate da leitura livre, descompromissada, "prazerosa", como dizem os alunos do estudo, uma vez que contribui de modo significativo para o hábito de ler. 
O papel da escola é de grande valia como incentivadora da leitura. Uma leitura como mediadora, realizada num ambiente informal, que proporcione um embarque em diferentes e inusitadas aventuras, a fim de provocar questionamentos, gerar dúvidas, reflexões e produção de entendimento e de idéias.

Uma leitura, para se tornar eficiente, precisa captar um volume considerável de informações que estão, de certa forma, estocadas na memória do leitor, vindo à tona quando acionadas, quando relacionadas a algo. Assim, conforme já se disse, haverá a compreensão se o texto lido for contextualizado, se encontrar ressonâncias, ou seja, se encontrar significações pertinentes, suscetíveis de provocar mudanças e novos comportamentos.

Para que haja essas ressonâncias, é necessário leitura. Porém uma leitura dialógica, que faça o educando pensar, raciocinar, explorar os aspectos lexicais e semânticos do texto. Pela Literatura resgatam-se valores, sentimentos, ideais e experiências humanas. Compete, portanto, à escola a responsabilidade por essa transformação do educando. É ela que, por meio de um ambiente rico e motivador, proporcionará a recuperação desses princípios, como também os utilizará para provocar o pensamento, a fim de que o jovem transforme-se, tornandose lingüisticamente emancipado, capaz não só de compreender o mundo em que vive como também de criar outros mundos, outras realidades.
Tanto a leitura como a interpretação continuam sendo assuntos polêmicos, porém, um fato é certo: o professor, em seu papel mediador, deve ser presença ativa, motivadora e provocadora, a fim de proporcionar o desenvolvimento mental e intelectual do educando.

No tocante ao ensino da Literatura, no Ensino Médio, mesmo sendo alunos com escolaridade maior (oito anos já realizados no Ensino Fundamental) há necessidade de iniciar por uma fase mais elementar, como a que estabelece relações entre os fatos.

Atualmente, inicia-se o estudo da Literatura na primeira série do Ensino Médio, a partir da Idade Média. Gradativamente, chega-se à época contemporânea na terceira série. $\mathrm{O}$ ideal consistiria em começar pelo final: Idade Contemporânea, Moderna e média. Desta forma, estar-se ia valorizando o meio do aluno, a sua época e seus interesses imediatos. Paulatinamente, do conhecido, do mais perto, passa-se ao desconhecido, para o mais distante, a fim de o aluno conscientizar-se de que a Literatura faz parte de sua vida, qualquer um pode criar, redigir fatos imaginários, fictícios.

É interessante, também, solicitar aos alunos uma pesquisa sobre os poetas anônimos de sua classe, de sua escola e, inclusive, de sua cidade. Por meio deste tipo de pesquisa, assim como de saraus, leituras, análises, debates e comparações dos textos colhidos com outros, de diferentes autores, o aluno irá construindo o seu 
saber. Além dos textos, cativam a atenção dos alunos outros recursos didáticos, como mostragem de pinturas e audição de músicas representativas.

Assim, o educando compreenderá que conforme a época, há a predominância de determinadas idéias. Num ir e vir, descobrirá os movimentos literários, constituirá seus pensamentos e, conseqüentemente, estará evoluindo, transformando-se cultural e emocionalmente. Partindo dos interesses dos alunos, do ensino contextualizado, é possível estabelecer interações entre o próprio aluno e seu ambiente, do qual retira recursos para o seu desenvolvimento.

Dessa forma, a escola também se transformará, será engajada, participante, inserida na cultura e na sociedade de sua época. As aulas tornar-se-ão mais produtivas e o professor estará se preocupando com o desenvolvimento do indivíduo, numa prática que envolve o social e o individual. O próprio aluno buscará seu conhecimento, tendo a seu lado o professor interlocutor, em perfeita interação.

\section{REFERÊNCIAS}

ABREU, M. Quem não lê e não escreve, da vida pouco desfruta, porém... In Revista Leitura Teoria \& Prática. Unicamp, Ano 13, n.24, p.28 - 31, dez., 1994.

BAKHTIN, M. Marxismo e filosofia da linguagem. Tradução de Michel Lahud e Yara F. Vieira. 3. ed. São Paulo: Hucitec, 1986. 195 p.

FARACO, C. E. M.; FRANCISCO, M. Língua e literatura. 15. ed. São Paulo:
Ática, v. 2, 1998.383 p.

FAZENDA, I. Práticas interdisciplinares na escola. 7. ed. São Paulo: Cortez, 2001. 147 p.

GERALDI, J. W. O Texto na sala de aula. 2. ed. Cascavel: Assoest, 1984. 125 p.

GOMES, L. da S. Leitura e ensino de Literatura no $2^{\circ}$ grau. Revista Leitura: Teoria e Prática. Porto Alegre, ano 13, n. 23, p. 32-36, jun. 1994.

KANITZ, S. Estimulando a curiosidade. VEJA, São Paulo, ano 36, n. 43, p. 20, out. 2003.

LIBÂNEO, J. C. Didática. 5. ed. São Paulo: Cortez, 1992. 259 p.

MAIA, J. D. Português: novo ensino médio. São Paulo Ática, 2000. 447 p.

MINAYO, M. C. S. O desafio do conhecimento - pesquisa qualitativa em saúde. São Paulo; Rio de Janeiro: Hucitec; Abrasco. 1998. 269 p.

MOISÉS, M. A Literatura brasileira através dos textos. 22. ed. São Paulo: Cultrix, 2000. 598 p.

NÚMEROS da Vergonha. Revista Ensino Superior. São Paulo: SEMESP, ano 4. n. 41 , p. $10-14$, fev. 2001

BRASIL. Ministério da Educação. Secretaria da Educação Média e Tecnológica. Parâmetros Curriculares Nacionais: ensino médio.Brasília: MEC, 1999. 360 p.

PARK, M. B. Histórias e leituras de almanaques no Brasil. Campinas: Mercado Aberto, 1999. 216 p.

PAULINO, G. Tipos de textos, modos de leitura. Belo Horizonte: Formato Editorial, 2001. $163 \mathrm{p}$.

RÖSING, T. M.K. Ler na escola para ensinar literatura no $1^{\circ}, 2^{\circ}$ e $3^{\circ}$ graus. 
Porto Alegre: Mercado Aberto, 1988. 156 p.

SALGADO, M. U. C. Um olhar inicial sobre a formação de professores em serviço. In Salto para o Futuro: Um olhar sobre a escola. Secretaria da Educação a Distância. Brasília: Ministério da Educação, SEED, 2000, p. 13-30.

SILVA, E. T. da. O ato de ler. fundamentos psicológicos para uma nova pedagogia da leitura. 8. ed. São Paulo: Cortez, 2000. $103 \mathrm{p}$.

SMOLKA, A. L. B. AAtividade da leitura e o desenvolvimento das crianças. Caderno Estudos da linguagem. Campinas, v. 29 , p. 25-41, 1995.

VIDAL, D. G. Práticas de leitura na escola brasileira dos anos 1920 e 1930. Modos de ler/formas de escrever: estudos de história da leitura e da escrita no Brasil. Luciano Mendes Faria et al. (Org.). 2.ed. Belo Horizonte: Autêntica, 2001, p. 87-115.

VIGOTSKY, L. S. A Formação social da mente. 6. ed. Tradução de José Cipolla Neto, Luís Silveira Menna Barreto, Solange Castro Afeche. São Paulo: Martins Fontes, $1998.161 \mathrm{p}$.

VIGOTSKY, L. S.; LURIA, A. R.; LEONTIEV, A. N. Linguagem, desenvolvimento e aprendizagem. São Paulo, Ícone Edup, 1988. 228 p.

WALLON, H. Psicologia e educação da infância. Lisboa: Editorial Estampa, 1975 (Coletânea).

Encaminhado em: 15/03/06

Aceito em: 20/05/06

Olhar de professor, Ponta Grossa, 9(1): 183-199, $2006 . \overline{199}$ 